\title{
The Improved BP Neural Network Model and Its Application in Enterprise Strategic Management Performance Measurement
}

\author{
Zhibin Liu $^{1}$ Peng Shen ${ }^{2}$ Shaomei Yang ${ }^{1}$ \\ ${ }^{1}$ Economics \& Management Department, North China Electric Power University, Baoding 071003, P. R. China \\ ${ }^{2}$ College of Economics and Trade, Agricultural University of Hebei, Baoding 071001, P. R. China
}

\begin{abstract}
To evaluate the enterprises strategic management performance scientifically and accurately, this paper proposes the improved BP neural network model which imports the adjustable activation function and the Levenberg-Marquardt optimization algorithm. The improved model not only can simulate the expert in evaluating the strategic performance and avoiding the subjective mistakes in the evaluation process, but also enhance the learning accuracy and the algorithm convergence speed greatly. The strategic management performance evaluation of 14 enterprises in Hebei Province shows that the improved model is stable and reliable, and this method to forecast the enterprises strategic management performance is feasible.
\end{abstract}

Keywords: Enterprise strategic management, Index systems, Improved BP neural network algorithm, Performance evaluation

\section{Introduction}

In information and knowledge economy era, the competition among enterprises has been extended in space and strengthened in time. In order to obtain long-term survival and sustainable development, the enterprises must pay more attention to their development strategy management. Therefore, enterprises need to construct a whole set of comprehensive and objective overall performance evaluation system. We may test and amend the enterprises' development strategy after considering the evaluation results, and evaluate the implementation effect about the enterprises' development strategy, then provide the basis for the adjustment of the development strategies and business strategies.

The enterprise strategic management performance evaluation is a systematic evaluation process, and a scientific and quantitative argumentation. There are many methods about the performance evaluation have been widely applied, such as: the analytic hierarchy process, the gray systematic evaluation, fuzzy comprehensive evaluation method, etc. However, these methods are subject to stochastic factors in the evaluation, and the evaluation results are influenced by subjective experience and knowledge limitations easily, which often with personal bias and onesidedness. In recent years, with the rapid development of the neural network that has the unique advantages - self-learning, self-organizing and selfadapting ability, it can overcome the influence of subjective factors and has been applied widely. This paper will use the BP neural network method to evaluate the enterprise strategic management performance synthetically.

\section{The basic principle of the improved BP neural network}

In 1943, American psychologist W McCulloch and mathematician $\mathrm{W}$ Pitts presented a simple neurons mathematical model, namely MP model, which created the theoretical research about the artificial neural network model. In 1980s, American physicist J. J. Hopfield proposed the feedback interlinkage network and defined the energy function, it is the function about the neuron state and connection weights, which can be used to solve optimization problems and associative memory. In 1986, D. E. Rumelhart and J. L. McClelland brought forward the back-propagation algorithm of multilayer feedforward network, called BP network or BP algorithm[1]-[3]. This algorithm is used to solve the problems that perceptron cannot settle, and it is the most widely used algorithm presently.

\subsection{The parameters determination of the improved BP neural network}


The BP neural network algorithm proposed by D. E. Rumelhart and J. L. McClelland makes the neural network to have the more practical and effective training methods. However, the BP neural network application in the complex system is restricted because the initial BP algorithm has the defects of the low efficiency and the slow convergence speed owing to the highly non-linear system. At present, most advanced researches have focused on the algorithm improvements, and this paper imports the adjustable activation function and the Levenberg-Marquardt optimization algorithm to enhance the learning accuracy and the algorithm convergence speed[4]-[7].

The input vector in the input layer is: $X \in R^{n}$, $\mathrm{X}=\left(\mathrm{x}_{0}, \mathrm{x}_{1}, \mathrm{x}_{2} \ldots, \mathrm{x}_{\mathrm{n}-1}\right)^{\mathrm{T}}$; the input vector in the first hidden layer is: $\mathrm{X}^{\prime} \in \mathrm{R}_{1}^{\mathrm{n}}, \mathrm{X}^{\prime}=\left(\mathrm{x}_{0}^{\prime}, \mathrm{X}_{1}^{\prime}, \mathrm{X}_{2}^{\prime} \ldots, \mathrm{X}_{\mathrm{n}-1}^{\prime}\right)^{\mathrm{T}}$, output vector is: $\mathrm{Y}^{\prime} \in \mathrm{R}^{\mathrm{m}}{ }_{1}, \mathrm{Y}^{\prime}=\left(\mathrm{y}_{0}^{\prime}, \mathrm{y}_{1}^{\prime}, \mathrm{y}_{2}^{\prime} \ldots, \mathrm{y}_{\mathrm{m}-1}^{\prime}\right)^{\mathrm{T}}$; the input vector in the second hidden layer is: $X^{\prime \prime} \in R^{n}$, $\mathrm{X}^{\prime \prime}=\left(\mathrm{x}_{0}{ }_{0}, \mathrm{X}_{1}{ }_{1}, \mathrm{x}_{2}{ }_{2} \ldots, \mathrm{x}_{\mathrm{n}_{2-1}}\right)^{\mathrm{T}}$, output vector is: $\mathrm{Y}^{\prime \prime} \in \mathrm{R}^{\mathrm{m}}{ }_{2}$, $\mathrm{Y}^{\prime \prime}=\left(\mathrm{y}_{0}{ }_{0}, \mathrm{y}_{1}, \mathrm{y}_{2}, \ldots, \mathrm{y}_{\mathrm{m}_{2}-1}\right)^{\mathrm{T}}$; the input vector in the output layer is: $\mathrm{X}^{\prime \prime} \in \mathrm{R}_{3}^{\mathrm{n}}{ }_{3}, \mathrm{X}^{\prime \prime \prime}=\left(\mathrm{x}^{\prime \prime}{ }_{0}, \mathrm{X}^{\prime{ }_{1}}, \mathrm{X}^{\prime \prime}{ }_{2} \ldots, \mathrm{X}^{\prime \prime}{ }_{\mathrm{n}-1}\right)^{\mathrm{T}}$, output vector is: $\mathrm{Y} \in \mathrm{R}^{\mathrm{m}}, \mathrm{Y}=\left(\mathrm{y}_{0}, \mathrm{y}_{1}, \mathrm{y}_{2} \ldots, \mathrm{y}_{\mathrm{m}-1}\right)^{\mathrm{T}}$. The weight value between the input layer and the first hidden layer is denoted with $\omega_{\mathrm{ij}}$, the threshold value is $\theta_{\mathrm{j}}$, the weight value between the first hidden layer and the second hidden layer is denoted with $\omega_{\mathrm{jk}}^{\prime}$, the threshold value is $\theta_{\mathrm{k}}^{\prime}$, the weight value between the second hidden layer and the final output layer is denoted with $\omega^{\prime \prime}{ }_{k l}$, the threshold value is $\theta^{\prime \prime}$, then the input and output in every layer neurons are met:

$$
\begin{aligned}
& \mathrm{x}_{\mathrm{j}}{ }_{\mathrm{j}}=\sum_{\mathrm{i}=0}^{\mathrm{n}-1} \omega_{\mathrm{ij}} \mathrm{x}_{\mathrm{i}}-\theta_{\mathrm{j}} \\
& \mathrm{x}_{\mathrm{k}}{ }_{\mathrm{k}}=\sum_{\mathrm{j}=0}^{\mathrm{m}_{1}-1} \omega^{\prime}{ }_{\mathrm{jk}} \mathrm{y}_{\mathrm{j}}^{\prime}-\theta_{\mathrm{k}}^{\prime} \\
& \mathrm{x}^{\prime \prime \prime}{ }_{1}=\sum_{\mathrm{k}=0}^{\mathrm{m}_{2}-1} \omega^{\prime \prime}{ }_{\mathrm{kl}} \mathrm{y}_{\mathrm{k}}-\theta^{\prime \prime}{ }_{1} \\
& \mathrm{y}_{\mathrm{k}}{ }_{\mathrm{k}}=\mathrm{f}_{\mathrm{k}}\left(\mathrm{x}{ }_{\mathrm{k}}\right) \\
& \mathrm{y}_{1}=\mathrm{f}_{1}\left(\mathrm{x}_{1}^{\prime \prime \prime}\right) \\
& y^{\prime}{ }_{j}=f_{j}\left(x^{\prime}{ }_{j}\right)
\end{aligned}
$$

The activation function $\mathrm{f}(\mathrm{u})$ is a nonlinear function. We normally choose sigrnoid function, $\mathrm{f}(\mathrm{u})=\frac{1}{1+\mathrm{e}^{-\mathrm{u}}}$.

\subsection{The learning process of the improved BP neural network}

The study process of the BP neural network can be divided into two stages: the first stage is toward pass, namely input sample data from the input layer, transmit signal forward, and calculate the corresponding output neuron of every layer according to the above formula that is not feedback and connected among the layers. The second stage, namely the back pass, If the error between the actual output of the output layer and the goal output doesn't fall into the scheduled precision range, the error signal returns along the original pathway to amend the weight value and threshold value. By the two iterative processes, we make the network to achieve convergence at last. At this time, the error reaches the scheduled range. In the multilayer BP neural network, given a set of sample data $(\mathrm{x}, \mathrm{t}), \mathrm{X} \in \mathrm{R}^{\mathrm{n}}, \mathrm{t} \in \mathrm{R}^{\mathrm{m}}$, when input $\mathrm{P}_{\mathrm{i}}$ th sample, namely $\left(\mathrm{x}^{\mathrm{p}_{1}}, \mathrm{t}^{\mathrm{p}_{1}}\right)$, we can calculate the network output $\mathrm{y}^{\mathrm{p}_{1}} \in \mathrm{R}^{\mathrm{m}}$, relative to the $\mathrm{x}^{\mathrm{p}_{1}}$ using the improved $\mathrm{BP}$ algorithm, then the error function is defined as:

$$
\varepsilon=\frac{1}{2} \sum_{1=0}^{\mathrm{m}-1}\left(\mathrm{t}^{\mathrm{p}_{1}}-\mathrm{y}^{\mathrm{p}_{1}}\right)
$$

To all samples, the total network error:

$$
\mathrm{E}=\frac{1}{2} \sum_{\mathrm{p}_{1}=1}^{\mathrm{p}} \sum_{\mathrm{l}=0}^{\mathrm{m}-1}\left(\mathrm{t}^{\mathrm{p}_{1}}-\mathrm{y}^{\mathrm{p}_{1}}\right)^{2}
$$

We enter into the second stage of the learning process, namely adjustment reversely the weight value and the threshold value, and revise every weight value $\omega_{\mathrm{nq}}$ :

$$
\Delta \omega_{\mathrm{nq}}=-\eta\left(\frac{\partial \mathrm{E}}{\partial \omega_{\mathrm{nq}}}\right)=-\sum_{\mathrm{p}_{1}=1}^{\mathrm{p}} \eta \frac{\partial \varepsilon}{\partial \omega_{\mathrm{nq}}}
$$

$\eta$ is the learning rate[8]-[15].

The learning process of the neural network is the process to seek the smallest of error E, but the traditional BP algorithm to complex networks, it very likely falls into local minimum value. This paper introduces the Levenberg-Marquardt optimization algorithm which can enhance the network convergence speed and reach the error range rapidly.

\section{BP neural network model of the enterprise strategy performance evaluation}

\subsection{The comprehensive indicator systems of enterprise strategic performance evaluation}

When evaluating the enterprise strategic performance, we should keep to the ideas and methods of system engineering, follow the principle of comprehensive, value correlation, scientific pragmatism, unity and cost-benefit, and construct the multi-objective 
comprehensive strategic performance evaluation system. The following factors are taken into account when we evaluate the enterprise strategy performance.

3.1.1. The strategic performance evaluation indicator systems about the employee lay

The enterprise strategy management is to emphasize the future development. The investments for the future enable enterprises to maintain their core competitiveness and form strategic competitive advantage. In the formation process of these advantages people is the key, because all the work need people to operation, so it is important of the staff study and training, quality improvement and mobilizing their work enthusiasm, which has a direct impact on the enterprise development potential. For this reason, it is proposed to establish the following indicators: (1) The percentage of graduates $\left(U_{1}\right) ;(2)$ The staff keeping rate $\left(\mathrm{U}_{2}\right)$; (3) The staff training costs ratio $\left(\mathrm{U}_{3}\right)$.

3.1.2. The strategic performance evaluation indicator systems about the organizational system and process lay

Organizational system and process performance evaluation are mainly on the production efficiency of machinery equipment (or product) and the information system capability. The production efficiency of the product is mainly related to the production cycle, product quality and cost. Machinery and equipment production efficiency is to reflect machinery and equipment utilization. The information system capability is the capability to gain the financial and non-financial information about the internal management and decision-making in time. Therefore, the information system capability is the essential element of the enterprise performance evaluation. (1) Organization and management efficiency $\left(\mathrm{U}_{4}\right) ;(2)$ Information system capability $\left(\mathrm{U}_{5}\right)$; (3) The production capacity utilization ratio $\left(\mathrm{U}_{6}\right)$; (4) Product certified ratio $\left(\mathrm{U}_{7}\right)$.

3.1.3. The strategic performance evaluation indicator systems about the innovation and technology lay

The enterprise innovation and technology lay is related with the investment scale and utilization efficiency of research and development expenses, the innovate ability of new products and new technology etc. According to the above analysis, the evaluation indicator systems of the innovation and technology lay are as follows: (1) The research and development expenses ratio; (2) The new product development ability $\left(U_{9}\right)$; (3) The investment return rate of new products $\left(\mathrm{U}_{10}\right)$; $(4)$ Technology yield ratio $\left(\mathrm{U}_{11}\right)$.
3.1.4. The strategic performance evaluation indicator systems about the customer lay

Carrying through the customer relation management, we may improve customer satisfaction continuously, expanding market share and achieve as much as possible value so as to achieve strategic objectives of the enterprise. So the strategic performance evaluation indicator systems about the customer lay are as follows: (1) Market Share $\left(U_{12}\right)$; (2) The relative market share $\left(U_{13}\right)$; (3) The client retention rate $\left(U_{14}\right)$; (4) The customer profitability $\left(U_{15}\right)$.

3.1.5. The strategic performance evaluation indicator systems about the strategic alliance lay

The strategic alliance aimed at improving the relations with other business enterprises (such as suppliers), realizing the relation change between enterprises from competition to partnership, which aim to achieve a win-win situation. The strategic performance evaluation indicator systems about the strategic alliance lay are as follows: (1) The delivery rate on time $\left(U_{16}\right)$; (2) Strategic synergy $\left(U_{17}\right)$; (3) Orders satisfaction rate $\left(\mathrm{U}_{18}\right)$.

3.1.6. The strategic performance evaluation indicator systems about the social responsibility lay

The strategic performance evaluation of the social responsibility lay is mainly about the enterprise' social responsibility and the contributions to the community and society and so on. These mainly include: (1) Social and ecological environment indicators $\left(\mathrm{U}_{19}\right)$; $(2)$ Social contribution rate indicator $\left(\mathrm{U}_{20}\right)$.

\subsection{BP neural network principle of the enterprise strategic performance evaluation}

We take the 20 indicator numerical values of describing the enterprise strategic performance as the input vector, and take the corresponding comprehensive testing results as the network expectation output. We take enough samples to train the network, make the relative error to meet the scheduled accuracy after ceaseless learning process. At this time the weight value and the threshold value hold by the neural network is the correct internal denotation acquired by the self-adaptive learning. Once the network has been trained, it could serve as an effective tool to evaluate the enterprise strategic performance. 


\subsection{The construction of the improved BP neural network model}

(1) S.K.Doherty and other scholars' studies have shown that three-layer feedforward neural network, namely the neural network only contains one hidden layer can approximate any nonlinear function relation with any accuracy. So we set up a three-tier feedforward neural network, the input layer neuron number is the above 20 indicators, the determination of the hidden layer neuron number has not to reach a unified theory yet. According to the experience, the node number of the hidden lay should meet $2 n>m$ (m denotes the input layer node number). Therefore, we select 7 network neurons for the hidden layer, and the neuron in the output layer is only one, namely the power enterprise financial risk comprehensive value.

(2) Network parameters initialized: we endow with the link weight value $\omega_{\mathrm{ij}}$ and the threshold value $\theta_{\mathrm{j}}$ between the input layer and the hidden layer, the link weight value $\omega_{\mathrm{jk}}^{\prime}$ and the threshold value $\theta_{\mathrm{k}}^{\prime}$ between the hidden layer and the output layer.

(3) Select a tier model randomly as the input signal.

(4) Calculate the input $x_{j}^{\prime}$ and the output $y_{j}^{\prime}$ of the hidden layer neurons.

(5) Calculate the input $x_{k}$ and the output $y_{k}$ of the output layer neurons.

(6) Calculate the general error $u_{k}$ of the output layer neurons, judge $u_{k}$ whether to meet demands, if met to step (9) and not met to step (7).

(7) Calculate the general ion errors of the hidden layer neurons:

$$
\mathrm{v}_{\mathrm{j}}=\left[\sum_{\mathrm{k}=0}^{\mathrm{m}-1}\left(\mathrm{u}_{\mathrm{k}} \omega^{\prime}{ }_{\mathrm{jk}}\right)\right] \mathrm{f}^{\prime}{ }_{\mathrm{j}}\left(\mathrm{x}_{\mathrm{j}}{ }_{\mathrm{j}}\right)
$$
value:

(8) The amending weight value and the threshold

$$
\begin{aligned}
& \omega^{\prime}{ }_{\mathrm{jk}}(\mathrm{N}+1)=\omega^{\prime}{ }_{\mathrm{jk}}(\mathrm{N})+\Delta \omega^{\prime}{ }_{\mathrm{jk}}(\mathrm{N}) \\
& \omega_{\mathrm{ij}}(\mathrm{N}+1)=\omega_{\mathrm{ij}}(\mathrm{N})+\Delta \omega_{\mathrm{ij}}(\mathrm{N}) \\
& \theta^{\prime}{ }_{\mathrm{k}}(\mathrm{N}+1)=\theta^{\prime}{ }_{\mathrm{k}}(\mathrm{N})+\Delta \theta^{\prime}{ }_{\mathrm{k}}(\mathrm{N}) \\
& \theta_{\mathrm{j}}(\mathrm{N}+1)=\theta_{\mathrm{j}}(\mathrm{N})+\Delta \theta_{\mathrm{j}}(\mathrm{N})
\end{aligned}
$$

(9) We take the next tier model as the input signal so as to all the training models train a circumference, until the total error reaches the scheduled accuracy. The learn process is terminated, otherwise we update the study frequency, then return to training again[16][20].

\section{Simulation experiment}

\begin{tabular}{|c|c|c|c|c|c|c|c|c|}
\hline No. & $\mathrm{U}_{1}$ & $\mathrm{U}_{2}$ & $\mathrm{U}_{3}$ & $\mathrm{U}_{4}$ & $\mathrm{U}_{5}$ & $\mathrm{U}_{6}$ & $\mathrm{U}_{7}$ & $\mathrm{U}_{8}$ \\
\hline 1 & 0.5 & 0.5 & 0.5 & 0.7 & 0.7 & 0.5 & 1 & 0.7 \\
\hline 2 & 1 & 0.7 & 1 & 1 & 1 & 1 & 1 & 0.7 \\
\hline 3 & 0.7 & 0.7 & 0.5 & 1 & 0.7 & 1 & 1 & 0.7 \\
\hline 4 & 0.7 & 0.7 & 1 & 0.7 & 0.7 & 0.5 & 0.7 & 0.5 \\
\hline 5 & 0.7 & 0.7 & 1 & 0.7 & 0.7 & 0.5 & 1 & 0.7 \\
\hline 6 & 0.7 & 1 & 1 & 0.7 & 0.7 & 1 & 0.7 & 0.7 \\
\hline 7 & 0.5 & 0.7 & 0.5 & 0.7 & 0.7 & 0.5 & 0.5 & 0.7 \\
\hline 8 & 0.5 & 0.5 & 0.5 & 0.5 & 0.7 & 0.3 & 0.3 & 0.5 \\
\hline 9 & 1 & 0.7 & 1 & 1 & 1 & 1 & 1 & 0.7 \\
\hline 10 & 0.7 & 0.7 & 0.5 & 0.7 & 0.7 & 0.5 & 0.7 & 0.5 \\
\hline 11 & 0.7 & 0.7 & 1 & 1 & 0.7 & 0.5 & 1 & 0.7 \\
\hline 12 & 0.7 & 0.5 & 0.5 & 0.7 & 0.7 & 0.5 & 0.7 & 0.7 \\
\hline 13 & 0.7 & 1 & 1 & 1 & 0.7 & 1 & 1 & 0.7 \\
\hline 14 & 0.7 & 0.7 & 0.3 & 0.5 & 0.3 & 0.5 & 0.3 & 0.5 \\
\hline
\end{tabular}

In this paper, we take the performance evaluation based on the improved BP neural network of 14 enterprises in Hebei Province as an example, which are shown in table 1.

Table 1: Expert evaluation data and the taxis

\begin{tabular}{ccccccccc}
\hline No. & $\mathrm{U}_{9}$ & $\mathrm{U}_{10}$ & $\mathrm{U}_{11}$ & $\mathrm{U}_{12}$ & $\mathrm{U}_{13}$ & $\mathrm{U}_{14}$ & $\mathrm{U}_{15}$ & $\mathrm{U}_{16}$ \\
\hline 1 & 1 & 0.7 & 0.7 & 1 & 1 & 0.7 & 0.7 & 0.7 \\
2 & 1 & 1 & 0.7 & 1 & 1 & 0.7 & 1 & 0.7 \\
3 & 1 & 1 & 0.7 & 1 & 1 & 0.7 & 0.7 & 0.7 \\
4 & 0.7 & 0.7 & 0.7 & 0.5 & 0.7 & 0.7 & 0.5 & 0.7 \\
5 & 1 & 0.7 & 0.7 & 1 & 1 & 0.7 & 0.7 & 0.7 \\
6 & 1 & 1 & 0.7 & 1 & 0.7 & 0.7 & 0.7 & 0.7 \\
7 & 0.5 & 0.7 & 0.7 & 0.5 & 0.7 & 0.5 & 0.7 & 0.7 \\
8 & 0.5 & 0.7 & 0.7 & 0.5 & 0.3 & 0.5 & 0.7 & 0.7 \\
9 & 1 & 1 & 0.7 & 1 & 1 & 0.7 & 0.7 & 0.7 \\
10 & 0.7 & 0.7 & 0.5 & 0.5 & 0.7 & 0.7 & 0.7 & 0.7 \\
11 & 1 & 1 & 0.7 & 1 & 1 & 0.7 & 0.7 & 0.7 \\
12 & 0.5 & 0.7 & 0.7 & 0.5 & 0.7 & 0.7 & 0.7 & 0.5 \\
13 & 1 & 1 & 0.7 & 1 & 0.7 & 0.7 & 0.7 & 0.7 \\
14 & 0.5 & 0.5 & 0.7 & 0.5 & 0.3 & 0.5 & 0.7 & 0.5 \\
\hline & & & Continued table & & &
\end{tabular}




\begin{tabular}{ccccccc}
\hline No. & $\mathrm{U}_{17}$ & $\mathrm{U}_{18}$ & $\mathrm{U}_{19}$ & $\mathrm{U}_{20}$ & Score & Taxis \\
\hline 1 & 0.7 & 0.7 & 0.7 & 0.1 & 0.713 & 8 \\
2 & 1 & 0.3 & 0.7 & 1 & 0.931 & 1 \\
3 & 0.7 & 0.7 & 0.7 & 0.5 & 0.766 & 6 \\
4 & 0.7 & 0.7 & 0.7 & 0.5 & 0.683 & 9 \\
5 & 1 & 0.7 & 0.7 & 0.1 & 0.727 & 7 \\
6 & 1 & 1 & 1 & 1 & 0.861 & 2 \\
7 & 0.7 & 0.7 & 0.7 & 0.5 & 0.604 & 12 \\
8 & 0.7 & 0.7 & 0.3 & 0.5 & 0.488 & 13 \\
9 & 1 & 1 & 0.7 & 0.1 & 0.810 & 5 \\
10 & 0.7 & 0.7 & 1 & 0.5 & 0.641 & 11 \\
11 & 1 & 0.7 & 1 & 0.5 & 0.827 & 3 \\
12 & 0.7 & 0.7 & 0.7 & 1 & 0.647 & 10 \\
13 & 0.7 & 0.7 & 1 & 0.5 & 0.817 & 4 \\
14 & 0.7 & 0.3 & 0.3 & 0.5 & 0.460 & 14 \\
\hline & & & Continued table & &
\end{tabular}

We use the MatLab to realize the software program, establish the three-layer BP neural network structure of enterprise performance evaluation, the given study accuracy $\mathcal{E}=0.0001$, and we select 7 network neurons for the hidden layer. We take 1-10 group enterprise performance evaluation data and evaluation results in table 1 as the training set, train the network, and carry through the simulation evaluation using the performance evaluation indicators data of the four residual groups and the trained network. In table 2, the network training results and the actual comprehensive evaluation results in the enterprise operating process are shown. The simulation results about the 4 test sets and the actual evaluation results, as shown in table 3 . The results in the table 2 and table 3 show that not only all the training samples is very close to the actual evaluation value, but the results of the four simulation test sets is also very close to the actual evaluation.

\begin{tabular}{lccc}
\hline No. & 1 & 2 & 3 \\
\hline Actual evaluation results & 0.7130 & 0.9310 & 0.7660 \\
Network training results & 0.7185 & 0.9193 & 0.7567 \\
Evaluating results taxis & 6 & 1 & 4 \\
Training results taxis & 6 & 1 & 4 \\
\hline
\end{tabular}

Table 2: The actual evaluation results compared with the network training results and the taxis

\begin{tabular}{|c|c|c|c|}
\hline No. & 4 & 5 & 6 \\
\hline Actual evaluation results & 0.6830 & 0.7270 & 0.8610 \\
\hline Network training results & 0.6890 & 0.7196 & 0.8612 \\
\hline Evaluating results taxis & 7 & 5 & 2 \\
\hline Training results taxis & 7 & 5 & 2 \\
\hline \multicolumn{4}{|c|}{ Continued table } \\
\hline No. & & 7 & 8 \\
\hline Actual evaluation results & & 6040 & 0.4880 \\
\hline Network training results & & 5029 & 0.4894 \\
\hline Evaluating results taxis & & 9 & 10 \\
\hline Training results taxis & & 9 & 10 \\
\hline \multicolumn{4}{|c|}{ Continued table } \\
\hline No. & & 9 & 10 \\
\hline Actual evaluation results & & 3100 & 0.6410 \\
\hline Network training results & & 3094 & 0.6343 \\
\hline Evaluating results taxis & & 3 & 8 \\
\hline Training results taxis & & 3 & 8 \\
\hline
\end{tabular}

Continued table

\begin{tabular}{lcc}
\hline No. & 1 & 2 \\
\hline Actual evaluation results & 0.8270 & 0.6470 \\
Network training results & 0.8289 & 0.6511 \\
Evaluating results taxis & 1 & 3 \\
Training results taxis & 1 & 3 \\
\hline
\end{tabular}

Table 3: The actual evaluation results compared with the simulation results and the taxis

\begin{tabular}{lcc}
\hline No. & 3 & 4 \\
\hline Actual evaluation results & 0.8170 & 0.4600 \\
Network training results & 0.8169 & 0.4509 \\
Evaluating results taxis & 2 & 4 \\
Training results taxis & 2 & 4 \\
\hline \multicolumn{2}{c}{ Continued table }
\end{tabular}

\section{Conclusions}


The enterprise strategic performance evaluation is associated with many factors, it needs large numbers of statistical calculation, and the factitious factors can be mixed into easily, which make the performance evaluation work is difficult. In this paper, we build the improved BP neural network model based on the analysis of the performance evaluation factors. It can not only overcome the limitations of the traditional evaluation methods and avoid the human errors in the evaluation process, but also enhance the learning accuracy and the algorithm convergence speed greatly. To the comprehensive evaluation problems of presenting the non-linear relation among the factors, it gives a more ideal outcome.

\section{Acknowledgement}

This research was supported by the Scientific Research Foundation for Young Teachers of North China Electric Power University. The item No. is 200611037.

\section{References}

[1] Q.C. Zhao, B. Wang, and Z. Liang, The application research and improvement of the enterprise comprehensive performance evaluation based on BP neural network. Industrial Engineering Journal, 3:102-107, 2005.

[2] X.Y. Li, and W.H. Xu, The model and application about the enterprise payoff ability evaluation based on the improved BP neural network. Industrial Technology Economy, 6:9296, 2006.

[3] J.G. He, G.Y. Jiang, and B. Tian, The credit evaluation system reaearch based on improved BP neural network. Computer Engineering and Design, 27:605-611, 2006.

[4] F. Ren, J.Q. Liu, and D.X. Niu, Comprehensive evaluation on sustainable development for electric power industry based on improved BP neural network model. Journal of North China Electric Power University, 33: 80-83, 2006.

[5] Z. Yuan, and B. Luo, Research on improved BP network. Information Technology, 2:88-91, 2006.

[6] Ridella S, and Rovetta S, Circular back propagation networks for classification. IEEE Trans on Neural Networks, 18:84-97, 1997.

[7] J. Karhunen, E. Oja, and L. Wang, A class of neural networks for independent component analysis. IEEE Trans on Neural Networks, 18: 486-504, 1997.
[8] L.F. Robert, Observer-participant model of neural processing. IEEE Trans on Neural Networks, 16:918-928, 1997.

[9] S. Lian, A conception of research to mechanism of enterprise crisis early-warning. Collection of ICMSE'96, pp.140-143, 1996.

[10] T. Hill, L. Marquez, and Marcus O'Ionnor, Artificial neural networks forecasting and deciding model. International Journal of Forecasting, 10:5-15, 1994.

[11] M. Mary, and S. Linda, A neural network model for estimating option. Journal of Applied Intelligence, 3:193-206, 1993.

[12] C. Wang, Study on enterprise organization Management system. The 4th Annual Meeting of China Soft-Science Association, Literature of science and technology press, pp.298-302, 1998.

[13] Y.H. Hsu, and H.M. Huang, Distribution system service restoration using a heuristic search approach. IEEE Trans on PWRD, 7:734-740, 1992.

[14] Y.Y. Hsu, and H.C. Kuo, A heuristic based fuzzy reasoning approach for distribution system service restoration. IEEE Trans on PWRD, 9: 948-953, 1994.

[15] N.K. Miu, H.D. Chiang, and B. Yuan, Fast service restoration for large-scale distribution system with priority customers and constraints. IEEE Trans on PWRS, 13:789-795, 1998.

[16] S.J. Lee, S.I.I. Lim, and B.S. Ahn, Service restoration of primary distribution systems based on fuzzy evaluation of multi-criteria. IEEE Trans on PWRS, 13:1156-1163, 1998.

[17] D.W. Tank, and J.J. Hopfield, Simple neural optimization networks, an A/D converter, signal decision circuit, and linear programming circuit. IEEE Trans on CAS, 33:533-541, 1986.

[18] M.P. Kenedy, Unifying the tank and hopfild linear programming circuit of Chua and Lin. IEEE Trans on CAS, 34:210-214, 1987.

[19] T. Nakagawa, Y. Hayashi, and S. Iwamoto, Neural network application to state estimation computation. IEEE Tran on CAS, 9:188-192, 1991.

[20] L.H. Xu, Y.L. Yu, Q.D. Wu, and J.H. Shi, General fuzzy neural network: theory and applications, Proceedings of 1999 IEEE International Fuzzy Systems Conference Proceedings, fuzzy-IEEE'99, pp.518-523, 1999. 